\title{
Successful use of therapeutic hypothermia in an opiate induced out-of-hospital cardiac arrest complicated by severe hypoglycaemia and amphetamine intoxication: a case report
}

\author{
Michael Busch*, Eldar Søreide
}

\begin{abstract}
The survival to discharge rate after unwitnessed, non-cardiac out-of-hospital cardiac arrest (OHCA) is dismal. We report the successful use of therapeutic hypothermia in a 26-year old woman with OHCA due to intentional poisoning with heroin, amphetamine and insulin.

The cardiac arrest was not witnessed, no bystander CPR was initiated, the time interval from the call to ambulance arrival was 9 minutes and the initial cardiac rhythm was asystole. Eight minutes of advanced cardiac life support resulted in ROSC. Upon hospital admission, the patient's pupils were dilated. Her arterial lactate was $17 \mathrm{mmol} / \mathrm{l}$, base excess $-20, \mathrm{pH}$ 6.9 and serum glucose $0.2 \mathrm{mmol} / \mathrm{I}$. During the first 24 hours in the ICU, the patient developed maximally dilated pupils not reacting to light and became increasingly haemodynamically unstable, requiring both inotropic support and massive fluid resuscitation. After 1 week in the ICU, however, she made an uneventful recovery with a Cerebral Performance Category of 1 at hospital discharge and at a follow up examination at 6 months.

Conclusion: According to most prognostic factors, the patient had a statistical chance for survival of less than 1\%, not taking into account her severe state of hypoglyaemia. We suggest that this case exemplifies the need for more studies on the use of $\mathrm{TH}$ in non-coronary causes of OHCA.
\end{abstract}

\section{Introduction}

Most primary survivors of out-of-hospital cardiac arrest (OHCA) will succumb to anoxic-ischemic brain injury during their hospital stay [1].

Among the factors known to predict a dismal prognosis are a non-cardiac cause of the OHCA, non-witnessed arrest, asystole as the initial ECG-rhythm, lack of bystander cardiopulmonary resuscitation (CPR) and time interval between distress call and arrival of the ambulance of more than 6 minutes [2]. Hypoglycaemic, anoxic-ischemic and amphetamine-caused brain injury share many pathophysiological pathways, such as oxidative stress, mitochondrial dysfunction, excitotoxicity, apoptosis, increased calcium influx, as well as increased seizure activity [3-7]. However, the role of therapeutic

\footnotetext{
* Correspondence: Bumi@sus.no

Department of Anesthesia and Intensive Care Medicine, Stavanger University Hospital, Postboks 8100, 4068 Stavanger, Norway
}

hypothermia $(\mathrm{TH})$ in OHCA due to non-cardiac causes (e.g., asphyxia or drug overdose) is not widely studied [8].

\section{Case report}

A 26-year old female sustained an OHCA after intentional poisoning. The cardiac arrest was unwitnessed, no bystander CPR was initiated, the interval from the call for help to the arrival of the ambulance and emergency physician was 9 minutes, the initial cardiac rhythm was asystole and the cause of the arrest was non-cardiac. After 8 minutes of standard advanced cardiac life support (including endotracheal intubation and i.v. injection of $2 \mathrm{mg}$ epinephrine and $3 \mathrm{mg}$ atropine, the patient developed a return of spontaneous circulation (ROSC). After the ROSC, the patient was haemodynamically stable and $\mathrm{TH}$ initiated with ice-packs. Her pupils were equal, dilated and not reactive to light. During transport

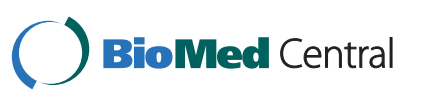


to the hospital, the patient was sedated with $10 \mathrm{mg}$ of diazepam due to irregular spontaneous respiratory efforts and received $500 \mathrm{ml}$ of crystalloid intravenously.

Upon hospital admission, the patient's tympanic temperature was $31^{\circ} \mathrm{C}$, and her ECG showed a sinus rhythm and nonspesific alterations of the ST-segment. Cerebral computer-tomography was normal. The chest $\mathrm{x}$-ray showed opacification of the lower right pulmonary lobe; pO2, pCO2 and $\mathrm{O} 2$ saturation were within normal limits. Laboratory findings are depicted in Table 1. Drug screening was positive for opiates, benzodiazepine, amphetamine, methamphetamine and ecstasy. The patient was transferred to the $I C U$ for standard postresuscitation treatment with sedation, controlled ventilation, close metabolic control and TH. The body temperature was maintained in the $\mathrm{TH}$ target range (32-34 C) for an additional 26 hours before controlled rewarming was commenced.

During glucose level control in the ICU a severe hypoglycaemia $(0.1 \mathrm{mmol} / \mathrm{l})$ was diagnosed and treated with $40 \mathrm{ml}$ of $50 \%$ glucose initially. This was followed by continuous glucose infusion for 20 hours to titrate glucose levels ranging from ranged from 4.1-8.2 mmol/l. The cumulative amount of glucose infused was $102 \mathrm{~g}$. When admission documentation was rechecked, it became apparent that a severe hypoglycaemia $(0.2$ $\mathrm{mmol} / \mathrm{l}$ ) had already been present at admission (i.e., 2.5 $\mathrm{h}$ before glucose treatment initiation). Shortly after admittance to the ICU, the patient developed maximally dilated pupils and became increasingly haemodynamically unstable, requiring inotropic and vasopressor therapy as well as substantial fluid resuscitation.
Echocardiography verified a significant post-cardiac arrest myocardial dysfunction with an ejection fraction of $30 \%$. The patient required 3 days of inotropic support before weaning was possible. After 8 hours of TH, the maximally dilated pupils decreased in size and became reactive to light. On day 2, pupillary size and reaction to light were normal.

During the course in the ICU, the patient required increasing doses of sedation, displayed spontaneous movements in all extremities and responded to endotracheal suctioning and positional change. After discontinuation of midazolam and fentanyl at day 7 , she became restless with spontaneous eye opening. Shortly thereafter, she displayed purposeful motion to stimuli. Weaning from mechanical ventilation was delayed by aspiration pneumonia and bilateral pleural effusions, but the patient was extubated on day 7 .

After transferral to the ward, her cerebral performance progressed continuously. The patient was graded as cerebral performance category (CPC) 1 [9] at hospital discharge. Six months later, a follow-up exam revealed no neurological or cardiovascular sequelae. The patient is currently in the second trimester of her first pregnancy.

The case is currently under investigation as an attempted homicide with the so-called "Judas-dose", a street term for the drug combination used in our patient (personal communication, Stavanger police department).

\section{Discussion}

The good outcome in our patient was very surprising. Her statistical prognosis for survival was dismal $[2,10]$. Boyd noted that survival only occurred after acute

Table 1 The patient's laboratory findings during the first 7 days after hospital admission

\begin{tabular}{|c|c|c|c|c|c|c|c|c|}
\hline Lab findings (reference limits) & Admission & ICU Day 1 & Day 2 & Day 3 & Day 4 & Day 5 & Day 6 & Day 7 \\
\hline $\begin{array}{l}\text { Troponin } \mathrm{T} \\
(\text { norm }<0,1 \mu \mathrm{g} / \mathrm{l})\end{array}$ & 0,3 & 0,62 & 0,72 & 0,31 & 0,31 & 0,2 & & \\
\hline Ejection fraction (norm > 53\%) & 30 & - & - & 45 & - & - & 55 & \\
\hline Vasopressor therapy & + & + & + & & & & & \\
\hline Mechanical ventilation & + & + & + & + & + & + & + & + \\
\hline $\begin{array}{l}\text { WBC } \\
\left(3,8-10,8 \times 10^{3} / \mu l\right.\end{array}$ & 32 & 16 & 15,5 & 7 & 7 & 8 & 6 & \\
\hline Platelets $\left(150-450 \times 10^{3} / \mu \mathrm{l}\right)$ & 132 & 115 & 79 & 24 & 38 & 58 & 71 & 104 \\
\hline PTT (20-36 sec.) & 65 & 45 & 38 & 36 & 30 & & & \\
\hline INR (norm 1,0) & 1,2 & 1,4 & 1,5 & 1,3 & 1,1 & 1,1 & & \\
\hline D-Dimer $(<0,5 \mathrm{mg} / \mathrm{l})$ & $>4$ & $>4$ & $>4$ & $>4$ & $>4$ & $>4$ & & \\
\hline $\mathrm{CRP}<10 \mathrm{mg} / \mathrm{l}$ & $<1$ & 7,5 & 84 & 126 & 78 & 46 & 35 & \\
\hline Creatinine $(61,9-106 \mu \mathrm{mol} / \mathrm{l})$ & 182 & 118 & 140 & 160 & 114 & 94 & 88 & \\
\hline Base excess $( \pm 2)$ & $-20,7$ & NR & NR & $N R$ & NR & NR & $N R$ & $\mathrm{NR}$ \\
\hline $\mathrm{pH}(7,35-7,45)$ & 6,9 & NR & NR & NR & NR & NR & $N R$ & NR \\
\hline Lactate $(0,55-2,2 \mathrm{mmol} / \mathrm{l})$ & 17,1 & $N R$ & NR & $N R$ & $N R$ & NR & $N R$ & $\mathrm{NR}$ \\
\hline ASAT (10-45 U/I) & 1927 & 1495 & 936 & 638 & 492 & & & \\
\hline
\end{tabular}


poisoning leading to OHCA if 1) the OHCA was witnessed by EMS personnel or 2) the Emergency Dispatch Centre was called prior to the OHCA [11]. The prognostic data from these studies $[2,10,11]$, however, are derived from patients not treated with $\mathrm{TH}$.

The neuroprotective mechanisms of $\mathrm{TH}$ have been mostly studied in anoxic-ischemic brain injury, but temperature-dependent neurotoxic mechanisms of hypoglycaemia-, and amphetamine- induced brain damage have also been recognized $[1,4,12-14]$. No clear correlation between the additive effect of concurrent hypoglycaemic and ischemic-anoxic insults exists, partly due to the difference in the degree and distribution of neuronal necrosis of the two neurotoxins [6].

Whether the low body temperature at admission indicates possible hypothermia before the OHCA is unclear because no on-scene temperature reading was available. The protective effect of pre-cardiac arrest hypothermia in asphyxial CA has been established in the rat model [15]. In our experience, the vigorous prehospital application of TH measures (e.g, undressing, ice pack application and unwarmed iv. infusions) may lead to admission temperatures below $34^{\circ} \mathrm{C}$ for OHCA survivors.

Post-cardiac arrest myocardial dysfunction is a common but usually transient finding in OHCA survivors, and it cannot be used as a prognostic parameter [1]. In approximately $90 \%$ of patients after OHCA, s-troponin is elevated [16]. This may reflect ischemia due to insufficient perfusion during OHCA, mechanical or electrical injury due to chest compression and defibrillation or causal myocardial infarction. Myocardial ischemia and infarction have also been associated with acute insulin poisoning in the literature [17].

\section{Conclusion}

Although our case does not prove that TH is neuroprotective in non-cardiac OHCA, we suggest that it supports the notion that $\mathrm{TH}$ might have an extended role in brain injury due to other aetiologies than cardiac caused, ischemic-anoxic OHCA. Our work also demonstrates that proposed prognostic factors from the pre$\mathrm{TH}$ era may need to be re-evaluated as we gain more experience with the use of $\mathrm{TH}$.

\section{Consent section}

Written informed consent was obtained from the patient for publication of this case report. A copy of the written consent is available for review by the Editor-in-Chief of this journal.

\section{Authors' contributions}

MB carried out the initial resuscitation, clinical follow-up of the patient and conceived the idea of possible publication of the case. MB and ES both participated equally in the literature research and the process of writing the manuscript. Both authors read and approved the manuscript.

\section{Competing interests}

The authors declare that they have no competing interests.

Received: 30 September 2009

Accepted: 29 January 2010 Published: 29 January 2010

\section{References}

1. Nolan JP, Neumar RW, Adrie C, Aibiki M, Berg RA, Böttiger BW, Callaway C, Clark RS, Geocadin RG, Jauch EC, Kern KB, Laurent I, Longstreth WT, Merchant RM, Morley P, Morrison $\amalg$, Nadkarni V, Peberdy MA, Rivers EP, Rodriguez-Nunez A, Sellke FW, Spaulding C, Sunde K, Hoek TV: Post-cardiac arrest syndrome: Epidemiology, pathophysiology, treatment, and prognostication A Scientific Statement from the International Liaison Committee on Resuscitation; the American Heart Association Emergency Cardiovascular Care Committee; the Council on Cardiovascular Surgery and Anesthesia; the Council on Cardiopulmonary, Perioperative, and Critical Care; the Council on Clinical Cardiology; the Council on Stroke. Resuscitation 2008, 79(3):350-79.

2. Herlitz J, Engdahl J, Svensson L, Ånquist KA, Young M, Holmberg S: Factors associated with an increased chance of survival among patients suffering from out-of-hospital cardiac arrest in a national perspective. Am Heart J 2005, 150:234-42.

3. Masayuki F, Kazuo O, Ken-Ischiro H, Toshisuke S, Syouji S, Yoshinobu I: Specific changes in human brain after hypoglycaemic injury. Stroke 1997, 28:584-587.

4. Polderman $\mathrm{KH}$ : Induced hypothermia and fever control for prevention and treatment of neurological injuries. Lancet 2008, 371:1955-96.

5. Cadet JC, Krasnova IN, Jayanthi S, Lyles J: Neurotoxcicity of substituted amphetamines. Molecular and cellular mechanisms. Neurotox Res 2007, 11:183-202.

6. Auer RN, Siesjo BK: Biological differences between ischemia, hypoglycemia, and epilepsy. Ann Neurol 1988, 24(6):699-707.

7. Warren MW, Kobeissy FH, Liu MC, Hayes RC, Wang KK: Ecstasy toxcicity: a comparision to methamphetamine and traumatic brain injury. J Addict Dis 2006, 4:115-23

8. Bernard S: Hypothermia after cardiac arrest: expanding the therapeutic scope. Crit Care Med 2009, 37(7):S227-33.

9. Booth $\mathrm{CM}$, Boone RH, Tomlison G, Detsky AS: Is this patient dead, vegetative, or severely neurologically impaired? Assessing outcome for comatose survivors of cardiac arrest. JAMA 2004, 291:870-9.

10. Engdahl J, Bång A, Karlson BW, Lindquist J, Herlitz J: Characteristics and outcome among patients suffering from out-of-hospital cardiac arrest of non-cardiac aetiology. Resuscitation 2003, 57:33-41.

11. Boyd JJ, Kuisma MJ, Alaspåå AO, Vuori E, Repo JV, Randall TT: Outcome after heroin overdose and cardiopulmonary resuscitation. Acta Anesthesiol Scand 2006, 50:1120-1124.

12. Agardh CD, Siesjø BK: The influence of hypothermia on hypoglycaemia induced brain damage in the rat. Acta Neuropathol 1992, 82:379-85.

13. Shin BS, Won SJ, Yoo BH, Kauppinen TM, Suh SW: Prevention of hypoglycaemia-induced neuronal death by hypothermia. J Cereb Blood Flow Metab 2009, 26:161-169.

14. Malberg JE, Sabol KE, Seiden LS: Co-administration of MDMA with drugs that protect against MDMA neurotoxicity produces different effects on body temperature in the rat. J Pharmacol Exp Ther 1996, 278:258-67.

15. Xiao F, Safer $P$, Radovsky A: Mild protective and resuscitative hypothermia for asphyxial cardiac arrest in rats. Am J Emerg Med 1998, 17-25.

16. Gubb NR, Fox KA, Cawood P: Resuscitation from out-of-hospital cardiac arrest: implications for cardiac enzyme estimation. Resuscitation 1996, 33:35-41.

17. Kamijo Y, Soma K, Fukuda M, Ohwada T: Myocardial infarction with acute insulin poisoning- a case report. Angiology 2000, 51:689-93.

doi:10.1186/1757-7241-18-4

Cite this article as: Busch and Søreide: Successful use of therapeutic hypothermia in an opiate induced out-of-hospital cardiac arrest complicated by severe hypoglycaemia and amphetamine intoxication: a case report. Scandinavian Journal of Trauma, Resuscitation and Emergency Medicine 2010 18:4. 